\title{
Meningkatkan Self Disclosure Siswa Menengah Kejuruan Menuju Era Society 5.0 dengan Art Psychotherapy
}

\author{
(Enhancing Vocational High School Students' Self Disclosure towards Society 5.0 \\ with Art Psychotherapy) \\ Helda Yusfarina Anggraini*, Nina Permata Sari, Ali Rachman \\ ${ }^{1}$ Universitas Lambung Mangkurat, Jl. Brigjend Hasan Basri, Kalimantan Selatan 70123, Indonesia \\ *Penulis korespondensi, Surel: 1710123220010@mhs.ulm.ac.id
}

Paper received: 23th-Jun-2021; revised: 25th-Aug-2021; accepted: 4th-Sep-2021

\begin{abstract}
Self Disclosure is essential for every individual to freely express himself and improve his emotional, cognitive, physical, and spiritual well-being. Art Psychotherapy can be used to increase Self Disclosure. This study aimed to determine the effectiveness of Art Psychotherapy in increasing Vocational high school students' Self Disclosure. A quasi-experimental design is used in this quantitative study. A total of six students of the eleventh grade Music Skills Program at SMK Negeri 4 Banjarmasin became the research sample selected using the purposive sampling technique. Art Psychotherapy is a treatment that is used and given in four meetings. The measuring instrument uses a scale of self-disclosure that has been tested for validity and reliability. Data analysis technique using Mann Whitney U Test and Wilcoxon Test. The result shows differences in the level of Self Disclosure before and after being given treatment. Overall, the technique is Art Psychotherapy effective for increasing Self Disclosure in vocational high school students.
\end{abstract}

Keywords: art psychotherapy; self disclosure; music

\begin{abstract}
Abstrak
Self Disclosure penting untuk dimiliki oleh setiap individu agar dapat dengan bebas mengekspresikan diri dan meningkatkan kesejahteraan emosional, kognitif, fisik, serta spiritual dalam diri. Penggunaan teknik Art Psychotherapy dapat meningkatkan Self Disclosure. Tujuan dari penelitian ini adalah untuk mengetahui keefektifan Art Psychotherapy dalam meningkatkan Self Disclosure siswa SMK. Penelitian ini menggunakan metode kuantitatif dengan rancangan quasi experimental design. Enam siswa kelas XI Program Keahlian Seni Musik SMK Negeri 4 Banjarmasin menjadi sampel penelitian yang dipilih menggunakan teknik purposive sampling. Art Psychotherapy adalah treatment yang digunakan dan diberikan sebanyak empat kali pertemuan. Alat ukur menggunakan skala Self Disclosure yang telah teruji validitas dan reliabilitasnya. Teknik analisis data menggunakan Mann Whitney U Test dan Wilcoxon Test. Hasil penelitian yang didapatkan yakni terdapat perbedaan tingkat Self Disclosure sebelum dan sesudah diberikan treatment. Secara keseluruhan, teknik Art Psychotherapy efektif untuk meningkatkan Self Disclosure pada siswa sekolah menengah kejuruan.
\end{abstract}

Kata kunci: art psychotherapy; self disclosure; musik

\section{Pendahuluan}

Masa sekolah menengah kejuruan merupakan waktu yang tepat bagi para siswa untuk mengembangkan jati diri (identitas) dan berbagai aspek dalam perkembangannya seperti aspek fisik, kognitif, sosial, emosi, moral, dan religius. Hal ini diperlukan agar siswa dapat membangun kepribadian yang produktif dan mampu membangun hubungan harmonis dalam keberagaman di kehidupannya. Kemampuan berinteraksi dengan lingkungan sosial merupakan hal yang penting untuk dapat dilakukan, dikarenakan melalui proses tersebut, seorang individu akan saling berkomunikasi satu sama lain sehingga hal yang terjadi pada 
interaksi tersebut dapat diterima dengan baik oleh lingkungan sosial yang terlibat di dalamnya (Xiao, 2018).

Self disclosure ialah proses pengungkapan diri yang dilakukan oleh individu secara sengaja dan sukarela sebagai bentuk penyampaian informasi tentang dirinya terhadap orang lain (Karyanti, 2018). Guna mengembangkan kemampuan atau potensi hidup tanpa tekanan dari pihak manapun, self disclosure sangat perlu untuk dimiliki setiap orang. Individu yang tertutup, akan cenderung mengungkapkan dirinya melalui media, seperti internet (Arslan \& Kiper, 2018; Attrill, 2012). Rains, Brunner, \& Oman (2016) menyatakan bahwa lingkungan sosial ikut memengaruhi kemampuan self disclosure seseorang. Apabila seorang individu mampu mengungkapkan dirinya dengan baik, maka lingkungan sosial akan cenderung menerima dirinya secara positif, demikian pula sebaliknya.

Perkembangan self disclosure seseorang saat akan memasuki Era Society 5.0 akan berkembang dan membangun interaksi dengan manusia lainnya melalui teknologi yang ada (Irwansyah, 2019). Era Society 5.0 adalah suatu era yang mengutamakan kecerdasan buatan yang mengintegrasikan ruang fisik dan juga dunia maya serta memiliki tujuan agar dapat memberikan kesejahteraan kepada manusia (Raharja, 2019). Era society 5.0 hadir dalam perkembangan zaman dan berfokus pada kemampuan diri dalam berpikir kritis, kemampuan pemecahan masalah (problem solving), dan kemampuan kreatif dengan memanfaatkan perkembangan digital yang ada. Pada era ini, manusia akan berkembang dan membangun interaksi dengan manusia lainnya melalui teknologi yang semakin dirancang khusus untuk memudahkan interaksi manusia dalam jarak jauh sekalipun. Sehingga, keterampilan bersosial manusia juga akan semakin berkembang sejalan dengan perkembangan era. Jika self disclosure tidak dimiliki oleh siswa, kemungkinan siswa akan tenggelam oleh arus globalisasi yang terus berkembang pesat. Oleh karenanya, self disclosure sangatlah penting untuk dimiliki para siswa guna membangun keterampilan bersosial yang baik saat memasuki Era Society 5.0.

Perkembangan self disclosure seseorang sebelum memasuki Era Society 5.0 dapat dilihat dari pola interaksi yang lebih sederhana dikarenakan adanya teknologi, ruang lingkup interaksi yang menjadi lebih luas serta berkembangnya kreativitas seseorang (Poluakan, Dikayuana, Wibowo, \& Raharjo, 2019). Saat akan memasuki Era Society 5.0, perkembangan self disclosure seseorang dapat terlihat dari interaksi yang dilakukan secara teknologi dan dirasakan seperti ruang nyata, adanya kemampuan kepemimpinan (leadership), literasi digital (digital literacy), komunikasi (communication), kecerdasan emosional (emotional intelligence), kewirausahaan (entrepreneurship), kewarganegaraan global (global citizenship), pemecahan masalah (problem solving), dan kerja tim (team work) (Sasikirana, 2020).

Siswa yang memiliki self disclosure akan saling membantu membangun hubungan sosial dirinya dengan lingkungan sekitarnya. Hal ini akan menghantarkan siswa pada fungsi self disclosure itu sendiri, yakni sebagai wadah pengungkapan emosi, menjadi upaya dalam memecahkan masalah, keabsahan sosial, kendali sosial, dan perkembangan hubungan (Pinakesti, 2016). Dampak yang akan dihadapi seseorang jika memiliki self disclosure yang rendah diantaranya: cenderung merasakan kesepian, rendahnya keterampilan interpersonal, kurangnya rasa percaya diri, takut akan penolakan, kesenjangan dalam lingkungan sosial dan merasa rendah diri. Peran bimbingan dan konseling dalam meningkatkan self disclosure siswa atau konseli sangat diperlukan. Bimbingan dan konseling ini dilaksanakan oleh seseorang yang 
ahli kepada seorang individu agar dirinya mampu menyelesaikan permasalahan yang tengah dihadapi dan mendapatkan kesejahteraan dalam hidupnya (Daryanto, 2015).

Berdasarkan hasil wawancara bersama ketua program keahlian seni musik di SMK Negeri 4 Banjarmasin, terdapat beberapa bentuk self disclosure siswa kelas XI Program Keahlian Seni Musik yakni: (1) sulit mengungkapkan emosi saat mengalami peristiwa baik maupun buruk, (2) sulit mencari pemecahan masalah dan menyelesaikannya secara bijaksana dan objektif, (3) sulit untuk beradaptasi, (4) kurang kepercayaan diri, (5) timbulnya rasa khawatir, ketakutan, dan kecemasan, (6) serta sulit membangun hubungan terhadap orang disekitar. Dampak yang akan dialami oleh siswa jika masalah tersebut tidak segera ditangani adalah: (1) munculnya rasa kecemasan yang berlebih, (2) munculnya depresi, (3) ketidakmampuan untuk berfikir secara efektif, inovatif, dan efisien, (4) sulit dalam menyesuaikan diri dengan lingkungan baru, dan (5) sulit dalam membangun hubungan interpersonal. Dengan demikian, maka layanan bimbingan konseling harus segera dilakukan untuk menanggulangi permasalahan self disclosure yang telah dialami oleh para siswa di kelas XI Program Keahlian Seni Musik di SMK Negeri 4 Banjarmasin.

Salah satu teknik menarik yang dapat digunakan dalam meningkatkan self disclosure adalah teknik art psychotherapy. Menurut Gussak dan Rosal (2015) art psychotherapy adalah penggabungan dari seni visual dan psikologi, sedangkan menurut Needs (2012) teknik art psychotherapy dapat diartikan sebagai proses pemberian bantuan kepada seorang individu agar mendapatkan kesejahteraan dalam hidupnya melalui suatu karya seni. Selama proses pemberian layanan kepada siswa, art psychotherapy digunakan sebagai teknik dalam layanan konseling kelompok.

Art psychotherapy dipilih sebagai upaya untuk meningkatkan self disclosure siswa dikarenakan merupakan teknik yang berfungsi untuk memberi informasi yang lebih atas karya seni yang telah dibuat konseli sebagai dasar penilaian perkembangan konseli bagi konselor, sebagai upaya katarsis emosi bagi konseli yang tidak dapat diungkapkan secara kata-kata, serta mengurangi tingkat stress (Nurcahyanti, 2017). Hal ini didukung oleh penelitian yang menyatakan bahwa art psychotherapy mampu membuat seorang siswa menuangkan emosi yang terpendam dalam dirinya (kemarahan pada usia remaja) (Johan, Johari, Al Sayed, Mohamad, \& Zubir, 2018). Tak hanya itu, art psychotherapy juga mampu mengobati PTSD, TBI, dan terjadi gangguan mood (Jones, Walker, Drass, \& Kaimal, 2018).

Music therapy dipilih dalam penelitian ini dari sekian banyak jenis kegiatan dalam art psychotherapy. Adapun aktivitas yang dapat dilakukan dalam music therapy ini adalah bermain instrumen, menyanyi, mendengarkan musik, ataupun membuat lirik. Keefektifan art psychotherapy telah banyak diteliti sebelumnya. Sebuah hasil penelitian menunjukkan hasil bahwa Art Psychotherapy dapat memobilisasi emosi orang tua dengan rentang usia 57-80 tahun (Glozman \& Naumova, 2014). Dan selanjutnya oleh Treisman (2019) dengan hasil art psychotherapy mampu menjadi katarsis emosi maupun pikiran bagi anak, sehingga mereka mampu berinteraksi sosial secara baik dengan teman sebayanya. Penelitian ini bertujuan menganalisis seberapa efektif teknik Art Psychotherapy dalam meningkatkan Self Disclosure menuju Era Society 5.0 pada siswa kelas XI Program Keahlian Seni Musik SMK Negeri 4 Banjarmasin. 


\section{Metode}

Penelitian ini merupakan penelitian eksperimen dengan rancangan desain adalah quasi experiment design yang berbentuk the non equivalent pretest-posttest group design. Rancangan desain ini menggunakan kelompok eksperimen dan kelompok kontrol dari kelas yang ada dengan memilih sampel yang diperkirakan memiliki keadaan atau kondisi yang sama (Taniredja \& Mustafidah, 2012).

Metode dalam penelitian ini adalah kuantitatif. Teknik penarikan sampel yang digunakan yakni dengan teknik penarikan sampel nonprobability sampling dengan menggunakan purposive sampling. Adapun kriteria subjek penelitian yang digunakan baik dalam kelompok kontrol maupun kelompok eksperimen yakni; (1) expression yaitu sulit mengungkapkan emosi saat mengalami peristiwa baik maupun buruk, (2) self clarification yakni sulit mencari pemecahan masalah dan menyelesaikannya secara bijaksana dan objektif, (3) social validation yakni tidak adanya timbal balik terhadap informasi yang telah individu sampaikan kepada orang lain, (4) social control yakni tidak adanya pembatasan informasi dalam proses keterbukaan diri kepada orang lain, dan (5) relationship development yakni sulit membangun hubungan terhadap orang disekitar.

Tabel 1. The Non Equlvalent Pretest-Posttest Group Design

\begin{tabular}{lccc}
\hline \multicolumn{1}{c}{ Kelompok } & Pretest & Treatment & Posttest \\
\hline Kontrol & $\mathrm{O}_{1}$ & - & $\mathrm{O}_{2}$ \\
Eksperimen & $\mathrm{O}_{3}$ & $\mathrm{X}$ & $\mathrm{O}_{4}$ \\
\hline
\end{tabular}

Pengambilan data dilaksanakan di SMK Negeri 4 Banjarmasin dengan subjek penelitian berjumlah 6 orang siswa, yang mana akan dibagi menjadi dua kelompok, dalam setiap kelompok terdiri dari tiga orang. Syarat subjek penelitian adalah siswa tersebut tercatat sebagai siswa kelas XI Program Keahlian Seni Musik SMK Negeri 4 Banjarmasin dan memiliki skor self disclosure yang rendah. Treatment dilakukan sebanyak empat kali dan test sebanyak dua kali. Awal penelitian dimulai dengan melancarkan tes 1 (pretest) kemudian dilakukan treatment berupa art psychotherapy sebanyak empat kali. Terakhir, dilancarkan tes 2 (posttest).

Terdapat dua instrumen yang digunakan, yakni instrumen perlakuan dan instrumen pengumpulan data. Instrumen perlakuan berupa panduan art psychotherapy untuk meningkatkan self disclosure siswa kelas XI program keahlian seni musik. Instrumen pengumpulan data berupa skala Self Disclosure 1, 2, 3 dan 4. Terdapat sejumlah pertanyaan sebanyak 33 butir pernyataan. Di dalamnya, terdapat pernyataan favourable dan unfavourable. Skala Self Disclosure ini dikembangkan berlandaskan pada teori dimensi Self Disclosure oleh Devito. Skala Self Disclosure ini diuji validitas dan reliabilitasnya. Uji validitas dilakukan secara uji statistik korelasi pearson product moment dan uji reliabilitas dengan uji statistik Alpha Cronbach. Uji statistik Wilcoxon digunakan untuk menganalisis perbedaan Self Disclosure awal dan akhir pada tiap kelompok. Kemudian untuk mengetahui perbedaan Self Disclosure antara kedua kelompok digunakan Mann Whitney U Test. 


\subsection{Hasil Uji Validitas}

Uji yang digunakan dalam penelitian ini adalah uji validitas internal yaitu mengkorelasikan skor setiap butir instrumen dalam skor totalnya. Rumus yang digunakan adalah Product Moment. Berdasarkan hasil uji validitas instrumen self disclosure, instrumen yang terdiri dari 60 butir dibagikan kepada 30 siswa dan sebanyak 33 butir dianggap valid, sedangkan 27 lainnya tidak valid.

\subsection{Hasil Uji Reliabilitas}

Berdasarkan hasil uji reliabilitas menggunakan Alpha Cronbach dengan taraf signifikansi 5\% diperoleh hasil $r$ hitung sebesar 0,911, sedangkan $r$ tabel 0,361. Karena $r$ hitung $>r$ tabel maka skala self disclosure tersebut reliabel.

\subsection{Hasil Uji Normalitas}

Berdasarkan hasil uji normalitas (Tabel 2) yang telah dilakukan, diperoleh pada Uji Shapiro Wilk Test nilai sig pre-test dan post-test eksperimen $=0,463>0,05=5 \%$. Sementara itu pada nilai sig pre-test kontrol $=0,637>0,05=5 \%$ dan nilai Sig post-test kontrol $=0,780>0,05$ $=5 \%$. Sehingga hasil tersebut menunjukkan bahwa sebaran data self disclosure memiliki distribusi normal.

Tabel 2. Hasil Uji Normalitas

\begin{tabular}{llccc}
\hline & Kelompok & \multicolumn{3}{c}{ Shapiro-Wilk } \\
& & Statistic & Df & Sig. \\
\hline Hasil Test & Pre-test eksperimen (art psychotherapy) & 0,923 & 3 & 0,463 \\
& Post-test eksperimen (art psychotherapy) & 0,923 & 3 & 0,463 \\
& Pre-test kontrol & 0,964 & 3 & 0,637 \\
& Post-test kontrol & 0,987 & 3 & 0,780 \\
\hline
\end{tabular}

\subsection{Hasil Uji Homogenitas}

Berdasarkan uji homogenitas (Tabel 3) pada distribusi skala self disclosure, diperoleh skor level statistik (untuk mengetahui seberapa besar kedua varian mempunyai kesamaan) = 0,500 dengan taraf signifikansi 0,519 ( $\mathrm{p}>0,05)$. Hasil tersebut menunjukkan bahwa sebaran data self disclosure memiliki kesamaan variansi sampel antara kelompok eksperimen dan kelompok kontrol.

Tabel 3. Hasil Uji Homogenitas

\begin{tabular}{llcccc}
\hline & & $\begin{array}{c}\text { Levene } \\
\text { Statistic }\end{array}$ & df1 & df2 & Sig. \\
\hline Angket Self & Based on Mean & 0,500 & 1 & 4 & 0,519 \\
Disclosure & Based on Median & 0,100 & 1 & 4 & 0,768 \\
& Based on Median and with adjusted df & 0,100 & 1 & 3,448 & 0,770 \\
& Based on trimmed mean & 0,455 & 1 & 4 & 0,537 \\
\hline
\end{tabular}




\section{Hasil dan Pembahasan}

\subsection{Hasil}

Data hasil penelitian ini didapatkan dengan membagikan instrumen. Pada tes 1 (pretest) dilancarkan instrumen self disclosure dan diperoleh hasil sebanyak enam orang siswa dengan skor terendah. Keenam siswa inilah yang kemudian menjadi subjek dalam penelitian yang kemudian dibagi menjadi dua kelompok. Kelompok eksperimen yang terdiri dari tiga orang dan kelompok kontrol terdiri dari tiga orang. Setelah tes 1 dilancarkan, kemudian dilakukan treatment berupa art psychotherapy sebanyak empat pertemuan. Kemudian dilakukan pengukuran kembali yaitu tes 2 (posttest) menggunakan instrumen self disclosure.

Hasil tes 2 menunjukkan adanya perubahan skor self disclosure pada kelompok eksperimen. Peningkatan pada dua orang siswa untuk kategori "tinggi" yakni terjadi pada siswa dengan kode A-3 dengan skor pre-test 52 meningkat menjadi 82 skor post-test dan siswa dengan kode A-15 dengan skor pre-test 53 meningkat menjadi 80 skor post-test, peningkatan pada satu orang siswa untuk kategori "cukup" pada siswa dengan kode A-8 dengan skor pretest 52 meningkat menjadi 70 skor post-test. Lalu untuk kelompok kontrol tidak terjadi peningkatan yang signifikan yang dapat dilihat dari dua orang siswa tetap pada kategori "rendah" yakni pada siswa dengan kode A-5 dengan skor pre-test 49 menjadi 52 skor post-test dan siswa dengan kode A-28 dengan skor pre-test 51 menjadi 53 skor post-test, serta satu orang siswa tidak mengalami peningkatan sama sekali atau skor tetap yakni siswa dengan kode B-5 dengan skor pre-test dan post-test 53.

Tabel 4. Hasil Pre Test dan Post Test Kelompok Eksperimen

\begin{tabular}{cccccccc}
\hline $\begin{array}{c}\text { Kode } \\
\text { Siswa }\end{array}$ & $\begin{array}{c}\text { Pre- } \\
\text { Test }\end{array}$ & Persentase & Kategori & $\begin{array}{c}\text { Post- } \\
\text { Test }\end{array}$ & Persentase & $\begin{array}{c}\text { Perbedaan } \\
\text { Pre-Test dan } \\
\text { Post-Test }\end{array}$ & Kategori \\
\hline A-3 & 52 & $52 \%$ & Rendah & 82 & $82 \%$ & 30 & Tinggi \\
A-8 & 50 & $50 \%$ & Rendah & 70 & $70 \%$ & 20 & Cukup \\
A-15 & 53 & $53 \%$ & Rendah & 80 & $80 \%$ & 27 & Tinggi \\
$\begin{array}{c}\text { Rata- } \\
\text { Rata }\end{array}$ & 51,67 & $51,67 \%$ & Rendah & 77,33 & $77,33 \%$ & 25,67 & Tinggi \\
\hline
\end{tabular}

Tabel 5. Hasil Pre Test dan Post Test Kelompok Kontrol

\begin{tabular}{cccccccc}
\hline $\begin{array}{c}\text { Kode } \\
\text { Siswa }\end{array}$ & $\begin{array}{c}\text { Pre- } \\
\text { Test }\end{array}$ & Persentase & Kategori & $\begin{array}{c}\text { Post- } \\
\text { Test }\end{array}$ & Persentase & $\begin{array}{c}\text { Perbedaan } \\
\text { Pre-Test dan } \\
\text { Post-Test }\end{array}$ & Kategori \\
\hline A-5 & 49 & $49 \%$ & Rendah & 52 & $52 \%$ & 3 & Rendah \\
A-28 & 51 & $51 \%$ & Rendah & 53 & $53 \%$ & 2 & Rendah \\
B-5 & 53 & $53 \%$ & Rendah & 53 & $53 \%$ & 0 & Rendah \\
$\begin{array}{c}\text { Rata- } \\
\text { Rata }\end{array}$ & 51 & $51 \%$ & Rendah & 52,67 & $52,67 \%$ & 1,67 & Rendah \\
\hline
\end{tabular}


Tabel 6. Hasil Uji Wilcoxon

\begin{tabular}{lllcc}
\hline & & N & Mean Rank & Sum of Ranks \\
\hline post_test - pre_test & Negative Ranks & $0^{\text {a }}$ & 0,00 & 0,00 \\
& Positive Ranks & $5^{\mathrm{b}}$ & 3,00 & 15,00 \\
& Ties & $1^{\mathrm{c}}$ & & \\
& Total & 6 & & \\
\hline
\end{tabular}

Tabel 7. Hasil Wilcoxon

\begin{tabular}{lc}
\hline & post_test - pre_test \\
\hline $\mathrm{Z}$ & $-2,023^{\mathrm{b}}$ \\
Asymp. Sig. (2-tailed) & 0,043 \\
\hline
\end{tabular}

Tabel 8. Hasil Uji Mann Whitney Test

\begin{tabular}{lc}
\hline & Self Disclosure Siswa \\
\hline Mann-Whitney U & 0,000 \\
Wilcoxon W & 40,000 \\
Z & $-1,967$ \\
Asymp. Sig. (2-tailed) & 0,042 \\
Exact Sig. [2*(1-tailed Sig.)] &, $038^{\mathrm{b}}$ \\
\hline
\end{tabular}

Berdasarkan tabel 4, dapat dilihat adanya perubahan skor subjek pada kelompok eksperimen dan kelompok kontrol dari tes 1 ke 2. Setelah dilakukan uji wilcoxon, didapatkan hasil significance yakni 0,043 , diketahui probabilitas $0,05(0,043<0,05)$ maka dapat diketahui bahwa terdapat perbedaan self disclosure sebelum dan setelah diberikannya perlakuan. Lalu dilakukan uji Mann Whitney Test, tes 1 dan tes 2 didapatkan hasil significance yakni 0,042, diketahui probabilitas di atas $0,05(0,042<0,05)$. Dengan demikian, dapat diketahui bahwa $\mathrm{H}_{0}$ ditolak dan $\mathrm{H}_{1}$ diterima yang berarti teknik art psychotherapy dalam layanan konseling kelompok efektif terhadap self disclosure siswa dan dapat diketahui dari peningkatan self disclosure sesudah diberikan teknik art psychotherapy dalam layanan konseling kelompok.

\subsection{Pembahasan}

Pembahasan hasil penelitian terdiri dari hasil temuan implementasi konseling kelompok dengan teknik art psychotherapy guna meningkatkan self disclosure siswa kelas XI Program Keahlian Seni Musik di SMK Negeri 4 Banjarmasin. Pemberian layanan konseling kelompok dengan menggunakan teknik art psychotherapy ini efektif diberikan pada siswa SMK yang secara keseluruhan masih berusia remaja. Pada usia ini, individu dipenuhi ketidakstabilan emosi yang dapat membuat mereka menjadi lebih mudah tersinggung. Jika hal ini terus dibiarkan maka akan dapat berdampak pada kehidupan sosial remaja yang akan menjadi lebih sulit untuk beradaptasi dengan lingkungan sekitarnya.

Sebuah penelitian menunjukkan bahwa music therapy memiliki manfaat menurunkan stress, meningkatkan well-being individu dan bahkan dapat dikembangkan sebagai media untuk optimalisasi perkembangan kemampuan penyandang autis (Geraldina, 2017). Selain itu penelitian lain juga menunjukkan bahwa music therapy dapat menurunkan rasa cemas dalam 
diri remaja yang ditinggalkan oleh orang-orang tersayang seperti keluarga ataupun teman dekat (Ispriantari, 2015). Dalam hal ini, maka dapat diketahui bahwa music therapy dapat memberikan pengaruh yang besar dalam keberlangsungan hidup seorang individu terutama pada usia remaja.

Keterlibatan musik dalam pemberian layanan kepada siswa SMK dapat menjadi pilihan yang baik dikarenakan musik sangat dekat dengan kehidupan para remaja. Hal ini dapat terlihat dari keseharian remaja yang cenderung banyak menghabiskan waktunya untuk menonton video musik ataupun mendengarkan musik. Setiap individu terutama remaja sering kali menggunakan musik sebagai media untuk mengekspresikan pikiran ataupun perasaan mereka. Musik menjadi suatu hal yang penting untuk remaja dan dapat memberikan pengaruh yang besar dalam media terapeutik pada kehidupan remaja (Yosephine, Satiadarma, \& Theresia, 2019).

Analisis data hasil tes 1 dan tes 2 menunjukkan bahwa treatment yang diberikan efektif untuk meningkatkan self disclosure siswa kelas XI Program Keahlian Seni Musik pada SMK Negeri 4 Banjarmasin. Hal ini dibuktikan dengan adanya peningkatan skor yang didapatkan oleh subjek. Dari keenam subjek penelitian, lima orang subjek menunjukkan adanya peningkatan skor dan satu orang subjek dengan skor tetap.

Hubungan sosial dalam hubungan masyarakat saat ini semakin berkembang pesat di dunia maya. Oleh karenanya Era Society 5.0 hadir untuk menjadi solusi dari kesenjangan sosial pada Era Revolusi 4.0. Setiap individu selalu memerlukan orang lain dan membutuhkan interaksi sosial dengan lingkungan sekitarnya dalam memenuhi kebutuhan hidupnya. Pada Era Society 5.0 kemampuan seseorang untuk dapat beradaptasi pada lingkungan sekitar sangat diperlukan. Apabila seseorang mampu beradaptasi dengan lingkungan sosialnya secara baik, maka akan terbangun proses interaksi sosial, melalui proses tersebutlah nantinya seorang individu akan dapat saling berkomunikasi satu sama lain dan mengaktualisasikan diri terhadap lingkungannya sehingga dapat memiliki kemampuan Self Disclosure dalam dirinya (Winarti, 2012).

Evans dan Dubowski (2001) dalam penelitiannya menemukan bahwa self disclosure dapat ditingkatkan dengan menggunakan teknik art psychotherapy, yaitu adanya peningkatan keterampilan sosial seseorang hingga mereka mampu secara terbuka mengekspresikan dirinya dengan dunia luar. Penelitian lainnya menunjukkan bahwa teknik art psychotherapy dapat membantu individu mengungkapkan pikiran ataupun perasaan secara tidak langsung dengan memanfaatkan karya seni (Muthmainnah, 2017). Dalam hal ini, teknik art psychotherapy merupakan teknik dengan aktivitas yang dapat berperan sebagai katarsis emosi. Tak hanya sebagai katarsis emosi, temuan baru yang didapatkan peneliti dalam penelitian ini yakni dengan terbukanya para siswa atas pikiran, perasaan, ataupun diri mereka maka akan dapat membantu mereka dalam beradaptasi dengan lingkungan sosial, lebih mudah dalam membangun hubungan interpersonal, dan lebih mudah dalam mencari problem solving atas masalah yang tengah dihadapi dengan saling berdiskusi bersama orang disekitar mereka.

Hasil penelitian yang telah dilangsungkan memberikan hasil akhir bahwa teknik Art Psychotherapy melalui layanan konseling kelompok efektif dalam meningkatkan Self Disclosure siswa. Pada siswa kelompok eksperimen, dua orang siswa mengalami peningkatan dengan kategori "tinggi" pada indikator kesediaan siswa secara sukarela dalam menceritakan pengalaman menyenangkan maupun tidak menyenangkannya, kesediaan siswa secara 
sukarela dan jujur dalam menceritakan selera, minat, maupun masa depannya dan satu orang siswa mengalami peningkatan dengan kategori "cukup" pada indikator kesediaan siswa dalam berbagi kisah tentang pengalaman menyenangkan dan tidak menyenangkan serta berbagi pandangan tentang rutinitas sekolah, agama, maupun masa depan. Sedangkan pada siswa kelompok kontrol, secara keseluruhan tidak mengalami peningkatan.

Secara keseluruhan hasil penelitian yang didapatkan menunjukkan bahwa dengan pemberian music therapy maka dapat meningkatkan kemampuan siswa dalam hal membangun hubungan interpersonal, meningkatkan kemampuan berkomunikasi, menurunkan rasa cemas, maupun meningkatkan kemampuan dalam mengelola emosi. Hasil penelitian yang didapatkan sejalan dengan penelitian yang telah dilakukan sebelumnya. Afdhal, Chundrayetti, dan Deswita (2021) menemukan bahwa kegiatan yang dilakukan dalam music therapy dapat meningkatkan kemampuan interaksi sosial seorang individu. Widiawati (2017) menemukan bahwa kemampuan komunikasi seseorang dapat ditingkatkan melalui music therapy, dan Yuliana, Pujiastuti, dan Hartati (2020) menemukan bahwa pemberian music therapy dapat meningkatkan kecerdasan emosi seseorang.

\section{Simpulan}

Berdasarkan hasil penelitian terdapat perbedaan Self Disclosure siswa antara sebelum dan sesudah diberikan treatment berupa Art Psychotherapy. Hasil ini dapat dilihat dari adanya perbedaan hasil skor antara pretest (tes 1) dan hasil posttest (tes 2) pada uji beda Self Disclosure, serta pengujian hipotesis yang menunjukkan hasil bahwa $\mathrm{H}_{0}$ ditolak dan $\mathrm{H}_{1}$ diterima. Dengan demikian, maka teknik Art Psychotherapy efektif dalam meningkatkan Self Disclosure pada siswa kelas XI Program Keahlian Seni Musik di SMK Negeri 4 Banjarmasin. Berdasarkan hasil penelitian, diharapkan para konselor dapat memanfaatkan teknik Art Psychotherapy sebagai salah satu cara alternatif yang dapat dilakukan untuk meningkatkan Self Disclosure siswa di sekolah.

\section{Daftar Rujukan}

Afdhal, F., Chundrayetti, E., \& Deswita, D. (2021). Systematic Review: Intervensi Terapi Musik terhadap Kemampuan Interaksi Sosial pada Anak Autisme. Jurnal Keperawatan Jiwa (JKJ): Persatuan Perawat Nasional Indonesia, 9(2), 243-250.

Arslan, N., \& Kiper, A. (2018). Self-Disclosure and Internet Addiction. Malaysian Online Journal of Educational Technology, 6(1), 56-63.

Attrill, A. (2012). Sharing Only Parts of Me: Selective Categorical Self-Disclosure Across Internet Arenas. International Journal of Internet Science, 7(1).

Daryanto, M. F. (2015). Bimbingan Konseling Panduan Guru BK dan Guru Umum. Yogyakarta: Gava Media.

Evans, K., \& Dubowski, J. (2001). Art therapy with children on the autistic spectrum: Beyond words. Jessica Kingsley Publishers.

Geraldina, A. M. (2017). Terapi Musik: Bebas Budaya atau Terikat Budaya? Buletin Psikologi, 25(1), 45-53.

Glozman, J. M., \& Naumova, V. A. (2014). Art-therapy as a method for mobilizing personal resources in the elderly. Psychology in Russia, 7(3), 80.

Gussak, D. E., \& Rosal, M. L. (2015). The Wiley handbook of art therapy. John Wiley \& Sons.

Irwansyah. (2019). Komunikasi Bermediasi dalam Masyarakat 5.0. Retrieved from http://m.mediaindonesia.com/opini/213626/komunikasi-bermediasi-dalam-masyarakat-50\&sa

Ispriantari, A. (2015). Pengaruh Terapi Musik Klasik Terhadap Penurunan Tingkat Kecemasan Remaja (13-18 Tahun) Yang Dirawat Inap. Jurnal Kesehatan Hesti Wira Sakti, 3(3), 6-11. 
Johan, S., Johari, K. S. K., Al Sayed, S. M. A., Mohamad, N. H. A. R., \& Zubir, N. M. (2018). Effects of Using Expressive Arts Therapy in Group Counseling on Managing Delinquent Adolescents' Anger. International Journal of Academic Research in Business and Social Sciences, 8(12), 2201-2293.

Jones, J. P., Walker, M. S., Drass, J. M., \& Kaimal, G. (2018). Art therapy interventions for active duty military service members with post-traumatic stress disorder and traumatic brain injury. International Journal of Art Therapy, 23(2), 70-85.

Karyanti. (2018). Dance Counseling. Yogyakarta: Deepublish.

Muthmainnah, M. (2017). PERANAN TERAPI MENGGAMBAR SEBAGAI KATARSIS EMOSI ANAK. Jurnal Pendidikan Anak, 4(1), 524-529. https://doi.org/10.21831/jpa.v4i1.12338

Needs, G. (2012). Art therapy: Foundation and form. InsideArts.

Nurcahyanti, D. (2017). Pendekatan art therapy pada mahasiswa yang mengalami academic burnout. University of Muhammadiyah Malang.

Pinakesti, A. R. A. (2016). Self-disclosure dan stres pada mahasiswa. University of Muhammadiyah Malang.

Poluakan, M. V., Dikayuana, D., Wibowo, H., \& Raharjo, S. T. (2019). Potret Generasi Milenial pada Era Revolusi Industri 4.0. Focus: Jurnal Pekerjaan Sosial, 2(2), 187-197.

Raharja, H. Y. (2019). Relevansi pancasila era industry 4.0 dan society 5.0 di pendidikan tinggi vokasi. Journal Of Digital Education, Communication, And Arts (Deca), 2(1), 11-20.

Rains, S. A., Brunner, S. R., \& Oman, K. (2016). Self-disclosure and new communication technologies: The implications of receiving superficial self-disclosures from friends. Journal of Social and Personal Relationships, 33(1), 42-61.

Sasikirana, V. (2020). Urgensi Merdeka Belajar Di Era Revolusi Industri 4.0 Dan Tantangan Society 5.0. E-Tech: Jurnal Ilmiah Teknologi Pendidikan, 8(2).

Taniredja, T., \& Mustafidah, H. (2012). Penelitian Kuantitatif. Bandung: Alfabeta.

Treisman, K. (2019). A kaleidoscope of ways of using art therapy within child-based contexts. International Journal of Art Therapy, Vol. 24, pp. 97-99. Taylor \& Francis.

Widiawati, S. (2017). Pengaruh Terapi Musik terhadap Perkembangan Komunikasi Anak Autis di Kiddy Autism Centre Kota Jambi Tahun 2011. Jurnal Ilmiah Universitas Batanghari Jambi, 14(2), 113-116.

Winarti, E. (2012). Pengembangan keperibadian: Self Disclosure-Interpersonal Skills-Ethichs. Lentara Ilmu Cendekia.

Xiao, A. (2018). Konsep Interaksi Sosial Dalam Komunikasi, Teknologi, Masyarakat. Jurnal Komunika: Jurnal Komunikasi, Media Dan Informatika, 7(2), 94-99.

Yosephine, Y., Satiadarma, M. P., \& Theresia, Y. (2019). Pengaruh Terapi Musik Terhadap Penurunan Perilaku Agresi Pada Remaja. Jurnal Muara Ilmu Sosial, Humaniora, Dan Seni, 3(2), 509-519.

Yuliana, A. R., Pujiastuti, S. E., \& Hartati, E. (2020). Efektivitas Terapi Musik Klasik dalam Meningkatkan Emosi Anak Sekolah Dasar. Jurnal Keperawatan Dan Kesehatan Masyarakat Cendekia Utama, 9(1), 46-56. 